\title{
Application of IOT in the Supply Chain of the Fresh Agricultural Products
}

\author{
Liheng Zhang \\ Department of Finance and Economics, Xinyang Agriculture and Forestry University, Xinyang, 464000, P.R. China
}

\begin{abstract}
With the development of IOT and economic progress, consumers demand has great changes for fresh agricultural products. But traditional agricultural supply chain model exist problems. To achieve Information management fresh produce supply chain, To achieve intelligent production cultivate fresh produce, To achieve the fresh produce cold chain logistics in transit monitoring, etc. This paper puts forward some Suggestions to solve problems.
\end{abstract} chain

Keywords-IOT; fresh agricultural products; agricultural supply

\section{INTRODUCTION}

State Council Development Research Center researcher Mr. Ho said, in the circulation process, China's annual 80 million tons of vegetable and fruit rot, economic losses $\$ 8.9$ billion accounted for $30 \%$ of the entire industry output value, agricultural rot loss rate of $25 \%$ - 30\%[1], which brought both safety risks, but also increased production costs. It is much higher than the loss rate of fresh agricultural products of some developed countries in European and American. Because fresh agricultural products supply chain information system is relatively perfect in these countries, the loss-rate of fresh agricultural products is within 5\%. Therefore, the research for fresh agricultural products supply chain, find the circulation efficiency, cost reduction methods. And with the help of IOT to build agricultural production safety and quality trace ability system, has become a fresh agricultural products rapid development. It is of immediate significance.

\section{Fresh Agricultural Supply CHAIN AND IOT}

\section{A. Fresh Agricultural Products}

Fresh produce is produced by the agricultural sector, then primary food isn't processed or only a little, not long at room temperature [2]. Generally it includes vegetables, fruits, meat, aquatic products and livestock products. Fresh produce is one of China's main grain consumers other than food, that it occupies a very important position in people's daily life consumption.

\section{B. Agricultural Supply Chain}

Agricultural supply chain is to produce a specific range of supply chain, which refers to the suppliers of agricultural products (including seeds, pesticides, fertilizers and other production materials suppliers), producers (producers of agricultural products), agricultural products processing enterprises, distributors (wholesalers and retailers) and consumers of agricultural products composed of a functional network chain. That is three-level supply chain (Figure I) which composed of agricultural producers, agricultural products processing enterprises, distributors and consumers of agricultural products [3]. Agricultural supply chain starts at the final consumers, and is connected by retail, processing, distribution and other aspects of the agricultural producers to form a vertical network system. Producer delivery product to consumers through the supply chain platform, consumers to demand feedbacks related information to the producers at the same time. The model of agricultural supply chain, especially closely related to consumers but closely related to the deterioration of fresh perishable agricultural is implemented supply chain management. It can not only ensure the stability and consistency of supply quality products, improve the quality and food safety of products to establish and enhance the reputation of the brand, to achieve value-added products, but also effectively reduce production, logistics and transaction costs.

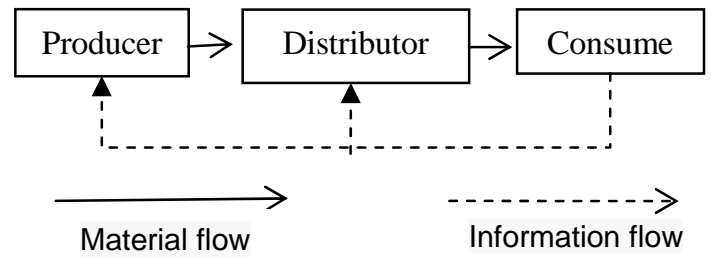

FIGURE I. THREE-LEVEL SUPPLY CHAIN

\section{IOT}

IOT, just as its name implies is something connected to the Internet. It is through the radio frequency identification technology, global positioning system (GPS) and other information sensing devices and the Internet [4]. Then it realizes the item information real-time information sharing, intelligent management of emerging technology, widely used in network integration. Thus it is an extension of the Internet, but isn't definitely the counterpart of the Internet.

IOT adapts to the characteristics of fresh agricultural products storage and transportation integration solutions. Around the characteristics of the fresh agricultural products supply chain, the construction set production, storage, holographic wisdom information system, billing and other functions in one of modern agricultural supply chain management system. 
III. The MeAning of IOT In the Fresh Agricultural SUPPLY CHAIN

\section{A. To Achieve Information Management Fresh Produce Supply Chain}

IOT as a modern information management strategy, through all other information sensing device such as the application of radio frequency identification connected items and the Internet, which realizes not only intelligent identification and management, but also seamless joint between physical space and digital space. IOT provides effective information technology support platform for green supply chain information, integration of resources, product life-cycle tracking and monitoring.

\section{B. To Achieve Intelligent Production Cultivate Fresh Produce}

Through IOT technology, intelligent high-density nurturing way can control and prevent the introduction and spread of disease from the source. Ecological information by installing wireless sensors and other intelligent control system in the production base, which are tested the production of the entire fresh produce nurturing environment. So we timely control some of the parameters affecting the nurturing environment. And we timely regulate farms that produce cultivation environment system according to parameter change to ensure good fresh produce grown in the environment, in order to increase production and ensure quality.

\section{To Achieve the Fresh Produce Cold Chain Logistics in Transit Monitoring}

The use of sensor technology, the integration of wireless sensor networks (WSN, Including ZigBee, GPRS, UMTS, etc.) and RFID technology warn cold fresh produce when cold chain temperature, humidity and product status change in road transportation [5]. Then we keep the adjustment environmental parameters cold chain during transportation, at the same time record the changes of the above information in the process of transportation. Thereby these help identify changes that may arise from these product quality problems, the specific time and location of occurrence, and further realize the transport of fresh produce in transit trace-ability. Fresh produce supply chain, which is advantageous for the upstream and downstream enterprises to facilitate timely query, real-time feedback during transport environmental information, to improve transport efficiency and reduce transportation risk, to reduce transportation costs, and to ensure the quality of fresh produce.

\section{To Achieve Management and Trace-ability of Fresh produce supply chain quality and safety}

On the one hand, the application of IOT ensure the efficient docking government quality supervision department of information systems and fresh produce supply chain information system, so that government regulators can realize the fresh produce to the sale of complete control from the upstream to the end in the entire supply chain process. On the other hand, RFID tags and sensors are recorded all aspects of the relevant information (temperature, light, product status, smell, etc.) [6], what is information about fresh agricultural products from the production, transportation and sales. And it is uploaded to the server over the wireless supply chain data dissemination network. Not only this is achieved real-time monitoring of the state of fresh agricultural products, to strengthen quality and safety management, but also this is achieved timely tracking the problem products and confirmation accident of accountability.

\section{PROBLEMS OF TRADITIONAL AGRICULTURAL SUPPLY CHAIN MODEL}

Fresh agricultural products supply chain in China are lack of unified information platform, production of the dispersion, the disequilibrium of market forces, uncertainty agricultural supply chain information, operation cost is relatively high.

\section{A. Sharing of Information Resources Exist Block, Lack of A Unified Information Platform}

Information resources can't be shared, what increases the cost of enterprise information utilization, puts off the real-time enterprise information utilization. Real-time information can't smoothly be passed on to each other in upstream and downstream supply chain. These conditions lead to supply chain stakeholders disjointed information, long time fresh agricultural products circulation, consumption and other issues. Then those hinder to the upstream enterprise know the sales and other downstream enterprise know the products situation, etc. These are information technology awareness of mainly companies in the supply chain isn't strong, the overall low level of information technology caused. The traditional model is still the dominant platform for its irreplaceable role and great development potential, so we shouldn't give up the advantages of accumulated construction market. Have broad participation approved farmers market platform has a great deal of flexibility for the adjustment of agricultural supply and demand and the labor market. So we should further regulate their operation, build its regulatory capacity to respond to market changes, and strengthen its basic support functions. At the same time, the leading platform for a greater role model range, what could evolve more value-added services and develop their potential.

\section{B. Production of the Dispersion}

Fresh agricultural products are mainly produced by individual farmers, the number of farmers, the small scale of production. In addition, the farmer lack of large financial support and production guidance of professional and technical personnel, the production efficiency of fresh agricultural products is relatively low. Every farmer will find his production impossibly achieve economies of scale, because his individual trivial production to market convergence has the huge transaction costs in all aspects from all aspects of production to the final consumers.

\section{The Disequilibrium of Market Forces}

In the household contract responsibility system, the majority of agricultural products are produced by the scattered farmers, scattered farmers at a disadvantage in and out of the supply chain. They are relatively shallow understanding of supply chain, and relatively weak for the sharing consciousness of information, which results in instability of the supply chain. When China vigorously promote agricultural business integration requires enterprises or farmers' cooperatives will be scattered farmers to organize. 


\section{Uncertainty Agricultural Supply Chain Information}

Agricultural production dispersion, the dispersion of regional as well as consumers dispersion what make the market highly fragmented information, so people difficultly grasp information on the market supply and demand, competitors and collaborators. Because China's rural market isn't standardized operation, and scattered farmer is also vulnerable in the "bullwhip effect" of the end, volatile information is difficult to grasp and effect. They are often blind production based on experience or the wrong signals, those result in "hard to buy" and "difficulty in selling" situation. Perishable agricultural product limits the agricultural products across regions and realtime adjustment that makes more risks of the supply chain.

\section{E. Operating Costs are Relatively High}

Our traditional fresh agricultural products supply chain hardware devices can't carry information demand, information consciousness is weak. Information degree isn't high on fresh agricultural products supply chain, the cost isn't balanced. High network costs accounted for $74.70 \%$ of total cost, seriously hindered the fresh agricultural products application scale. The second is the personnel cost $20.40 \%$, equipment maintenance is $3.60 \%$, system maintenance is $1.30 \%$ (figure II) [7]. Needs to be stable, accurate, continuous, automatic, low-cost, low power consumption, simple and easy to use, easy to maintain Internet to reduce costs.

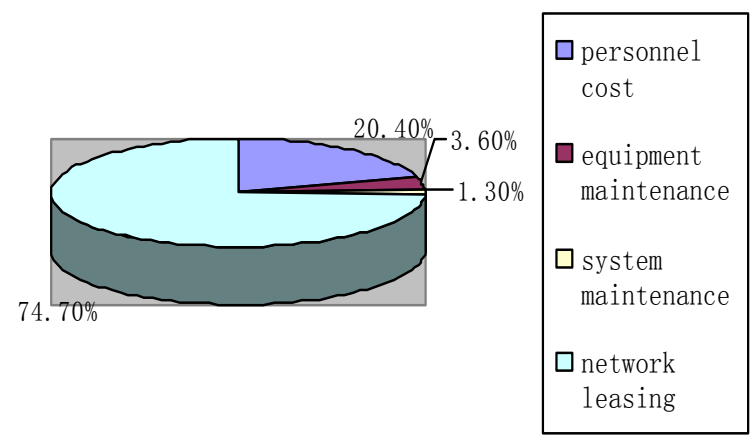

FIGURE II. COST SCALE MAP

\section{F. Fresh Agricultural Product Quality Safety Management Has Loophole}

Because of fresh agricultural products supply chain has no unified information platform, information of fresh agricultural products come from different companies, such as production, transportation, inspection, processing and sales information, etc. The decentralized information can't implement unified management. If once fresh agricultural products have safety problems, we are unable to trace the source, responsibility isn't clear. This is fresh agricultural products supply chain security and quality management system isn't unified, there is block information circulation.

\section{APPLICATION OF IOT IN THE FRESH PRODUCE SUPPLY CHAIN}

\section{A. The Intelligent Production}

Production cultivate fresh produce is the source of the entire fresh produce supply chain, production process of fresh produce under IOT not only can intelligent, but also can improve production efficiency and ensure the quality of fresh produce. For example, production nurturing ways is now widely used to achieve the fresh produce in greenhouse factory. Namely, advanced facilities and equipment is controlled the temperature, light, humidity, soil nutrient concentration, soil $\mathrm{pH}$ and other factors in greenhouses, then fresh produce will be cultivated high-density, high-yield.

\section{B. Determine The Cultivation of Agricultural Aspects of Environmental Indicators}

First plant characteristics and growth environment of fresh agricultural products are analyzed to determine the best environmental indicators and factors suitable for growing crops, and to monitor the development of standards. Then we realtimely monitor through IOT and sensor equipment for crop growth and nurturing environment, the monitoring data is automatically adjusted after nurturing environment compared to standard environmental indicators, in order to achieve intelligent production of fresh produce cultivation purposes.

\section{To Establish Production Control System of Fresh Agricultural Products Based On IOT}

Intelligent production, cultivation and control system of fresh produce based on IOT mainly has environmental monitoring, remote control, SMS notification and other functions. The use of IOT and computer technology real-timely monitors and early warns environmental factor on the growth phase of agricultural products, such as temperature, light, humidity, soil, etc. If there are problems, the system can deal with or promptly notify the staff.

\section{To Control Cold Chain Logistics in Transit}

Cold chain logistics in transit control is an important area of IOT used in the fresh produce supply chain. Since the fresh produce is perishable, it highly requires transport properties of the environment. IOT mainly through a remote information processing and control system transit transport implementation control fresh produce cold chain logistics.

\section{E. The Quality and Safety Management and Trace-ability}

Fresh farm produce quality and safety management is not only the need to safeguard social stability, consumers' health and safety, but also the inherent requirements of the fresh produce supply chain efficiency. The introduction of IOT improves regulatory measures and regulatory efficiency in the government quality supervision department. At the same time, it provides a guarantee of quality management and information technology for internal fresh produce supply chain integration.

\section{F. Agricultural Supply Chain Risk Control in IOT}

Purpose of supply chain risk control is to identify, control and avoid method. It overall optimizes the supply chain from the practical point of view, thereby enhancing the value of the entire supply chain. In the case of supply chain risk levels exceed the normal range of fluctuation will lead to the collapse of the entire supply chain. Information security risk has led market participants can't effectively identify false information, so collaborators' credit risk may be decreased inaccurate and other causes in the course of external cooperation. Improve the flow of information standards, norms flow of information 
channels, increase the flow of information, the reviews are very important. In particular to strengthen the Ministry of Information issued a qualified audit people to reduce information security risks from the information source.

\section{CONCLUSION}

About IOT of fresh agricultural products supply chain construction involves the use of RFID, WSN, GPS, GPRS, GIS, etc. It ensures process of the fresh agricultural products to visual trace ability, regulatory, and control ability from the production to the consumers table. Ensure that regulators and consumers interest subjects related to view information timely, truly "prior warning or control", as far as possible to reduce the loss.

Fresh agricultural products supply chain of the information platform system structure (figure III).The supply chain of Internet public information platform, upstream and downstream enterprises join each other in all the supply chain, is the formation of the point-to-point intelligent supply chain service system. Smooth flow of information achieves timely transfer sharing of information between supply chain upstream and downstream enterprises. Then it realizes the whole process control in the production, processing, logistics to terminal sales each link. Can also realize the supply chain in a product's production, circulation and recall for timely tracking and supervision, realize the production, transportation, sales and product recall process seamless docking. Enhance transparency of management, each enterprise quickly response to market changes in the supply chain, timely response to the risk of uncertainty.

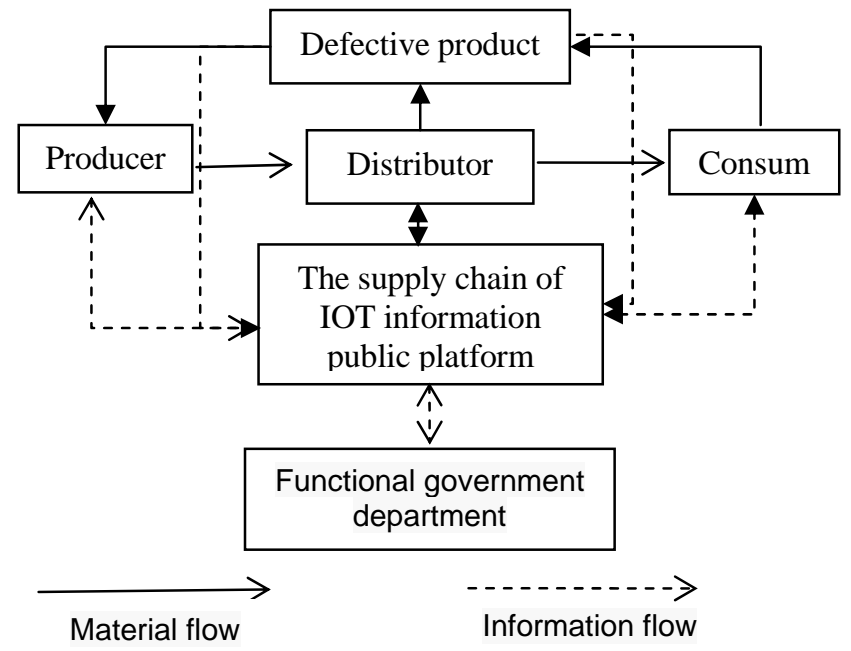

\section{FIGURE III. FRESH AGRICULTURAL PRODUCTS SUPPLY CHAIN SYSTEM OF INFORMATION PLATFORM}

\section{ACKNOWLEDGMENT}

The work is supported by the funds of the Project of Education Department of Henan Province (2016-zd-030), Soft science research project of Henan province (162400410138) and the Planning Project of Xinyang Social Science (2015JJ021).

\section{REFERENCES}

[1] ITU Internet Reports 2005: The Internet of Things [EB/OL]. http://www.itu.int/Internet of thins/, 2010-09-15.

[2] Boehije,M. \& L.F. Schrader. The Industrialization of Agriculture: Questions of Coordination in the Industrialization of Agriculture[M].Great Britain: The Ipswich Book Company,2000.121130.

[3] Hong-Mei Gao. Application of IOT in agricultural products supply chain management field. Commercial Age, 2010 (22) : 40-41.

[4] Lin Lu, Liu Feng-Shan. Agricultural products supply chain management research field based on Internet of things. Modern Agriculture, 2012 (7): 57-59.

[5] Sun Xiao-Tao. The construction of agricultural product logistics information standardization [J]. Hubei agricultural science, 2012:7.

[6] Ye-Jun Feng. Application of the Internet of things technology to build an efficient agricultural logistics system [J]. Logistics engineering and management, 2013:3.

[7] Xu-Hui Wang, Jilin Zhang. Based on the Internet of things of fresh agricultural products cold chain logistics system construction: framework, mechanism and path [J].Nanjing agricultural university (Social science edition), 2016 (1):31-43 